\title{
Pembuatan Administrasi Users Account Shell Linux Menggunakan PHP
}

\section{Making the Users Account Administration Linux Shell Using PHP}

\author{
Edy Victor Haryanto ${ }^{1}$, Rama Saputra Ginting ${ }^{2}$ \\ ${ }^{1,2}$ Universitas Potensi Utama, Jl. K. L. Yos Sudarso Km. 6,5 No. 3 A Tj. Mulia - Medan \\ edyvictor@gmail.com, rama_saputra@gmail.com
}

\begin{abstract}
Abstrak
Dalam mengatur konfigurasi user Linux tidak terlalu mudah bagi seorang yang selalu berpergian karena untuk dapat mengaturnya harus berhadapan dengan computer dan linux tersebut. Maka dari itu dalam penelitian ini membuat sebuah fasilitas remote control berbasiskan desktop bagi pengguna yang ingin mengaksses Linux tersebut dimana saja. Untuk mengatasi hal itu buat suatu aplikasi dapat mengakses linux dan mengatur konfigurasinya melalui web browser, yang dapat diakses dimana saja dan kapanpun. Dalam penelitian ini software yang dDigunakan fungsi dalam PHP yaitu PHP Exec yang berfungsi untuk mengkonversi perintah yang diketikan pada web browser menjadi perintah yang dikenali dalam sistem operasi Linux dan dengan menggunakan pemrogramman Bash. Hasil yang akan didapatkan adalah sebuah aplikasi berbasiskan web browser yang mampu mangkonfigurasi user Linux dengan secara online, dengan beberapa fitur tambahan yang digunakan untuk melengkapi aplikasi ini.
\end{abstract}

Kata Kunci : Linux, PHP Exec, Shell Linux, User Account

\begin{abstract}
In configuring the Linux user is not very easy for a person who regularly travel is due to be set to deal with the computer and linux. Therefore in this study makes a remote control facility-based desktop for users who want greater access to the Linux anywhere. To overcome this, create an application can access linux and set the configuration via a web browser, which can be accessed anywhere and anytime. In this study, the software used functions in PHP is PHP Exec which serves to convert the commands typed in a web browser into commands that are recognized in the Linux operating system and using the Bash programming. The results to be obtained is a web browser-based application that is capable mangkonfigurasi Linux users with online, with some additional features that are used to complete this application.
\end{abstract}

Keynote : Linux, PHP Exec, Shell Linux, User Account

\section{PENDAHULUAN}

Aplikasi administrasi user Linux masih sangat sedikit yang menggunakannya karena aplikasi pengendali terhadap Linux ini membutuhkan pengawasan lebih untuk menjaga agar tidak pergunakan dengan tidak semestinya.

Berdasarkan paparan keadaan tersebut di atas, sebuah instansi yang memiliki memiliki jaringan komputer disarankan untuk memiliki sebuah aplikasi administrasi user Linux jika komputer pada jaringan tersebut memiliki sistem operasi Linux. Sehingga sistem tersebut dapat dikonfigurasi dari manapun.

Salah satu solusi yang ditawarkan adalah aplikasi administrasi user shell Linux. Aplikasi ini adalah suatu metode untuk mengkonfigurasi sebuah sistem Linux dari jarak yang jauh sehingga kita dapat mengatur dan mengadministrasi user sistem Linux hanya dengan bermodalkan web 
browser. Dengan melihat uraian masalah di atas, maka dalam hal ini penulis membuat suatu rancangan aplikasi yang nantinya diharapkan dapat mengatasi masalah pengadministrasian user sistem Linux yang digunakan darimana pun kita berada dibanding kita harus mengkonfigurasinya secara langsung.

Tujuan yang ingin dicapai melalui penulisan penelitian ini adalah untuk mengenalkan bagaimana mudahnya mengkonfigurasi sistem Linux melalui Shell Linux jika sudah terbiasa dan dengan bantuan pemrogramman $B A S H$, mempermudah dan mengefisienkan kerja seorang administrator sistem Linux karena menggunakan protokol http dapat menambah user account dengan hanya online dari internet.

Menurut Yuswira dalam penelitiannya merancang jaringan komputer dan autentikasi serta database server yang berfungsi untuk membuat account seorang user dalam penggunaan internet, apabila pulsa internet habis maka server secara otomatis langsung menutup akses untuk internet[1], pada penelitian ini hanya membuat usere account untuk penggunaan internet dan pada penelitian saya dapat membuat user account linux dengan melalui web browser dan online.

\section{METODE PENELITIAN}

Sistem operasi linux adalah sistem operasi yang bersifat open source dan untuk mengatur konfigurasinya dapat dilakukan dengan cara :

a. GUI yaitu dapat mengkonfigurasi dengan berbantuan tampilan

b. TUI (Text User Interface) adalah dapat mengkonfigurasi sistem operasi linux dengan menggunakan perintah yang dituliskan pada shell linux, atau berbasis teks dan perintah tersebut dapat dilakukan dengan $P H P$ karena $P H P$ dapat mengirimkan perintah dari fungsi-fungsi $P H P$ tersebut.

Pada sistem ini, PHP mengubah protokol remote pada sistem operasi linux menjadi protokol web, dengan menggunakan hak akses root yang tidak terbatas pada sistem operasi linux, dan terminal linux tersebut akan dikendalikan dengan menggunakan plain text yang dikirim dari web browser

Semua kata kunci atau password dalam sistem Linux akan disimpan di /etc/passwd atau letc/shadow. Tetapi ketika kita mencoba membukanya ('cat /etc/shadow') muncul 1 baris katakata yang sulit dimengerti yang dipisahkan dengan tanda titik dua.

root:x:0:0:root:/root:/bin/bash

tiko:x:1000:1000:tiko,,,:/home/tiko:/bin/bash

root $->$ nama pengguna yang digunakan pada waktu login (panjang karakter antara 1-32)

$\mathrm{x}->$ password yang telah dienkripsi (di-scramble)

- 0 (pertama) -> user ID (UID). Untuk root maka UID-nya adalah 0 sedang selain root (user umum) adalah antara 1-99, sedangkan untuk sistem administrasi dan sistem account/grup antara 100-999.

- 0 (kedua) -> group ID (GID), biasanya disimpan di file /etc/group

root $->$ kolom komentar tentang informasi UID

/root $\rightarrow$ path absolut (mutlak/paten) sebagai direktori untuk user di mana ini merupakan folder tempat default setelah pengguna login. Maksudnya setelah login dan masuk sistem utama, ketika kita mengetikkan sudo su maka yang direktori yang muncul adalah /root karena memang telah didefinisikan sebelumnya bahwa user root direktori default-nya di /root. Untuk user lain misalnya "tiko" maka path default-nya adalah /home/tiko.

/bin/bash $\rightarrow$ merupakan perintah Shell yang telah diset untuk root. Maksudnya, jika user root ingin Shell yang digunakan bukan/bin/bash diganti, misalnya menggunakan /bin/sh atau /bin/csh.

\section{HASIL DAN PEMBAHASAN}


Desain sistem ini berisikan tentang file-file bash yang berekstension .sh sebagai file yang mengkonfigurasi sistem secara otomatis, dan sistem yang dirancang ini memiliki fungsi antara lain :

a. Memiliki kemampuan untuk mengkonfigurasi administrasi user linux

b. Mampu mengetahui spesifikasi web server yang digunakan

c. Dapat melakukan tugas administrasi sistem secara otomatis menggunakan file bash.

Linux sebagai sistem operasi yang sifatnya open source (kode - kode dapat dimodifikasi dan disebarluaskan), untuk mengadministrasi sistemnya dapat dilakukan dengan dua cara :

a. GUI (Grafical User Interface), yaitu mengkonfigurasi sistem dengan tampilan.

b. TUI (Text User Interface), yaitu mengkonfigurasi sistem dengan perintah yang di tuliskan pada Shell Linux. Untuk tingkat yang lebih lanjut, seperti membackup sistem, merencanakan otomatisasi sistem Linux hidup ataupun mati, hanya bisa dilakukan dengan modus TUI. Modus TUI atau yang biasa disebut dengan teks saja, dapat dimanfaatkan oleh $P H P$, karena $P H P$ mampu mengirimkan perintah dari fungsi fungsinya.

Sistem yang berjalan adalah bagaimana PHP mengubah protokol remote pada Linux, diubah menjadi protokol web browser. Dengan menggunakan hak akses root yang tidak terbatas pada sistem Linux, kita akan membuat teminal Linux dapat dikendalikan dengan plain text yang dikirimkan dari sebuah web browser.

3.1. Input

Adapun input yang terjadi pada aplikasi ini adalah :

a. Aplikasi yang berjalan, dalam penginputan data menggunakan metode POST berupa text yang dijalankan pada web browser.

b. File konfigurasi yang di edit pada sistem Linux melalui Web Browser.

3.2. Proses

Adapun proses yang terjadi pada pengadministrasian adalah :

a. Kita mengetikan perintah yang dikenali Linux pada web browser.

b. Perintah yang kita ketikan berupa plain text dikirimkan lewat web browser dengan metode POST ke dalam web server Linux yang sedang berjalan.

c. Dalam web server, perintah yang datang di ubah dengan sebuah fungsi PHP yang bernama php exec function menjadi sebuah perintah langsung kedalam sistem dengan menggunakan hak akses root.

\subsection{Output}

Output ataupun hasil keluaran yang akan dihasilkan adalah berupa laporan pada web browser bahwa perintah berhasil dilaksanakan, untuk setiap perintah yang berbeda menghasilkan hasil yang berbeda pada tampilan web browser.

Tampilan yang didapat web browser merupakan hasil dari metode GET yang dibuat pada kode PHP itu sendiri.

Diagram Konteks

Adapun diagram konteks pada aplikasi ini adalah (Gambar 1):

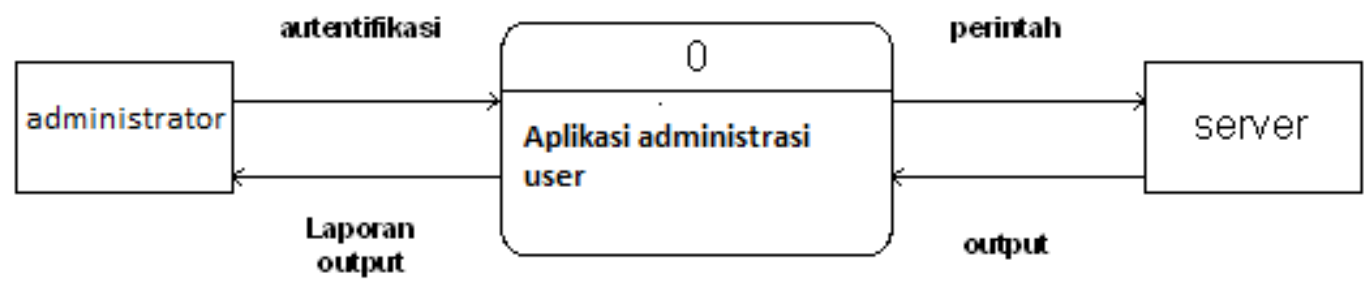

Gambar 1. Diagram Konteks Perancangan Administrasi Linux

Dari diagram konteks diatas dapat diperoleh penjelasan bahwa:

1. Administrator atau pengguna sistem melakukan autentifikasi untuk masuk. 
2. Kemudian sistem akan menterjemahkan perintah yang diberikan oleh pengguna kedalam perintah yang bisa dibaca oleh server.

3. Server akan memberikan respon berdasarkan perintah yang diberikan.

4. Kemudian server akan memberikan output hasil kepada sistem.

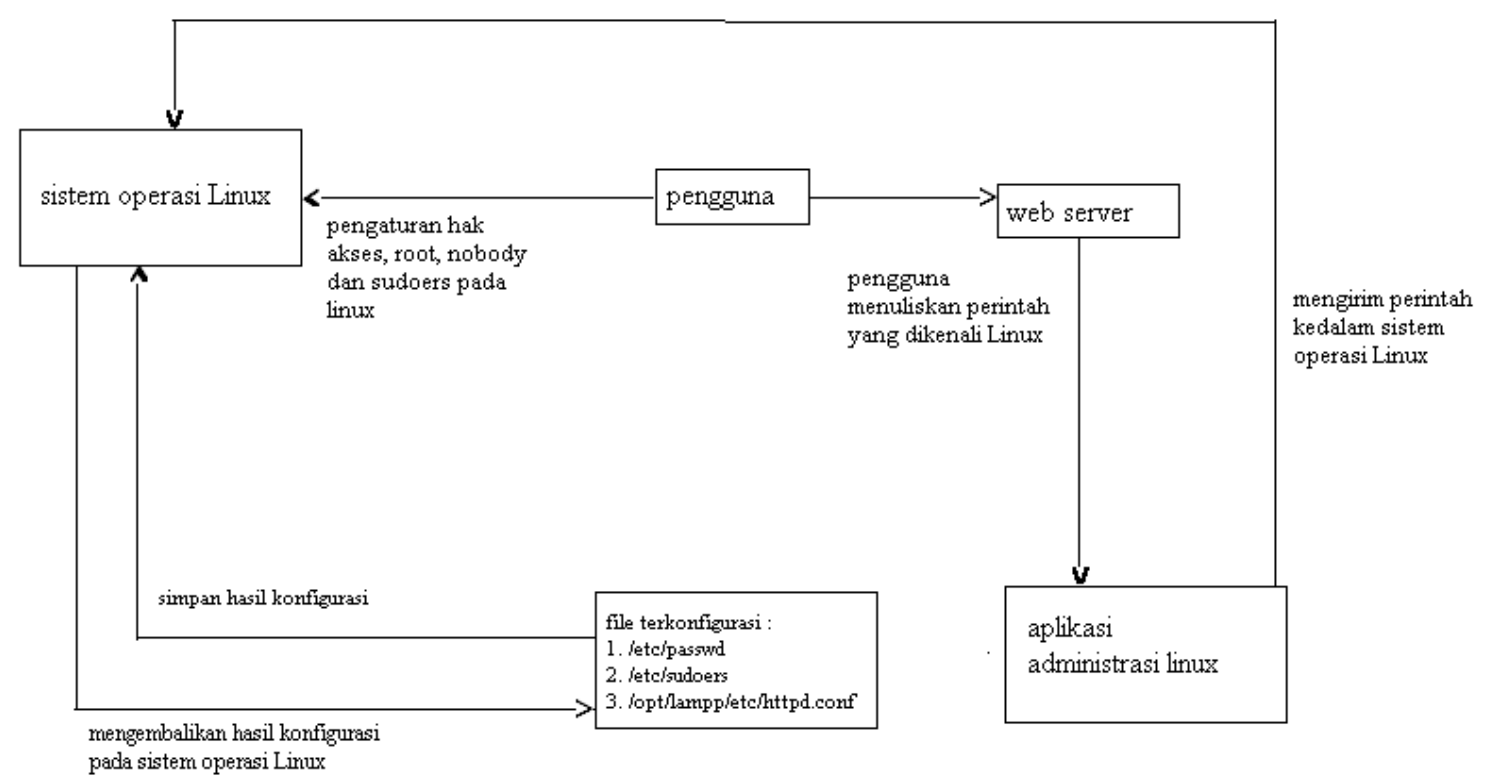

Gambar 2. Diagram Blok Perancangan Administrasi Linux

Dari diagram blok pada Gambar 2, didapatkan penjelasan :

1. Pengguna menginstall server dan web server sesuai dengan spesifikasi.

2. Dilakukan beberapa konfigurasi pada sistem operasi.

Ada 2 file yang perlu dikonfigurasi pada Linux, agar user Linux dapat diadministrasi oleh pengguna aplikasi web browser.

Pertama adalah file /etc/passwd, file ini berisikan informasi tentang password, username, groups, dan shell yang akan digunakan.

Berikut adalah isi file /etc/passwd yang belum di konfigurasi :

root:x:0:0:root:/root:/bin/bash

daemon:x:1:1:daemon:/usr/sbin:/bin/sh

bin:x:2:2:bin:/bin:/bin/sh

sys: $x: 3: 3:$ sys:/dev:/bin/sh

sync: $x: 4: 65534:$ sync:/bin:/bin/sync

games:x:5:60:games:/usr/games:/bin/sh

man:x:6:12:man:/var/cache/man:/bin/sh

lp:x:7:7:lp:/var/spool/lpd:/bin/sh

mail:x:8:8:mail:/var/mail:/bin/sh

news:x:9:9:news:/var/spool/news:/bin/sh

ииср:x:10:10:uиср:/var/spool/uucp:/bin/sh

proxy:x:13:13:proxy:/bin:/bin/sh

www-data:x:33:33:www-data:/var/www:/bin/sh

backup:x:34:34:backup:/var/backups:/bin/sh

list:x:38:38:Mailing List Manager:/var/list:/bin/sh

irc:x:39:39:ircd:/var/run/ircd:/bin/sh

gnats:x:41:41:Gnats Bug-Reporting System (admin):/var/lib/gnats:/bin/sh

nobody:x:65534:65534:nobody:/nonexistent:/bin/sh

dhcp:x:100:101::/nonexistent:/bin/false

syslog:x:101:102::/home/syslog:/bin/false 
klog:x:102:103::/home/klog:/bin/false messagebus:x:103:107::/var/run/dbus:/bin/false avahi:x:104:108:Avahi mDNS daemon,,,:/var/run/avahi-daemon:/bin/false cupsys:x:105:109::/home/cupsys:/bin/false haldaemon:x:106:110:Hardware abstraction layer,,,:/var/run/hal:/bin/false hplip:x:107:7:HPLIP system user,,,:/var/run/hplip:/bin/false gdm:x:108:113:Gnome Display Manager:/var/lib/gdm:/bin/false avahi-autoipd:x:110:119:Avahi autoip daemon,,,:/var/lib/avahi-autoipd:/bin/false festival:x:109:29::/home/festival:/bin/false libuuid:x:111:120::/var/lib/libuuid:/bin/sh polkituser:x:112:122:PolicyKit,,,:/var/run/PolicyKit:/bin/false pulse:x:113:123:PulseAudio daemon,,,:/var/run/pulse:/bin/false

Perintah konfigurasi sistem Linux adalah:

1. userdel nobody. Perintah ini ditujukan untuk menghapus user nobody yang sudah ada. Alasan user nobody di hapus karena pada sistem operasi Linux, user yang mengakses sistem Linux melalui web browser dinamakan user nobody. User nobody memiliki shell /bin/sh, shell /bin/sh tidak mempunyai hak dan kemampuan untuk mengadministrasi sistem lebih lanjut.

2. useradd nobody $-m-g$ root $-s$ /bin/bash. Setelah pengguna nobody dihapus, maka kita ciptakan lagi user nobody yang memiliki shell /bin/bash dan dimasukan dalam grup root.

Perintah diatas menghasilkan perubahan pada file /etc/passwd, berikut perubahannya : root:x:0:0:root:/root:/bin/bash daemon:x:1:1:daemon:/usr/sbin:/bin/sh bin:x:2:2:bin:/bin:/bin/sh sys:x:3:3:sys:/dev:/bin/sh sync:x:4:65534:sync:/bin:/bin/sync games:x:5:60:games:/usr/games:/bin/sh man:x:6:12:man:/var/cache/man:/bin/sh lp:x:7:7:lp:/var/spool/lpd:/bin/sh mail:x:8:8:mail:/var/mail:/bin/sh news:x:9:9:news:/var/spool/news:/bin/sh ииср:x:10:10:uисp:/var/spool/uucp:/bin/sh proxy:x:13:13:proxy:/bin:/bin/sh www-data:x:33:33:www-data:/var/www:/bin/sh backup:x:34:34:backup:/var/backups:/bin/sh list:x:38:38:Mailing List Manager:/var/list:/bin/sh irc:x:39:39:ircd:/var/run/ircd:/bin/sh gnats:x:41:41:Gnats Bug-Reporting System (admin):/var/lib/gnats:/bin/sh dhcp:x:100:101::/nonexistent:/bin/false syslog:x:101:102::/home/syslog:/bin/false klog:x:102:103::/home/klog:/bin/false messagebus:x:103:107::/var/run/dbus:/bin/false avahi:x:104:108:Avahi mDNS daemon,,,:/var/run/avahi-daemon:/bin/false cupsys:x:105:109::/home/cupsys:/bin/false haldaemon:x:106:110:Hardware abstraction layer,,,:/var/run/hal:/bin/false hplip:x:107:7:HPLIP system user,,,:/var/run/hplip://bin/false gdm:x:108:113:Gnome Display Manager:/var/lib/gdm:/bin/false avahi-autoipd:x:110:119:Avahi autoip daemon,,,:/var/lib/avahiautoipd:/bin/false festival:x:109:29::/home/festival:/bin/false libuuid:x:111:120::/var/lib/libuuid:/bin/sh 
polkituser:x:112:122:PolicyKit,,,:/var/run/PolicyKit:/bin/false pulse:x:113:123:PulseAudio daemon,,,:/var/run/pulse:/bin/false nobody:x:1001:0::/home/nobody:/bin/bash

Kedua adalah file /etc/sudoers, file ini berisikan informasi tentang pengguna yang bisa menggunakan perintah "sudo". Sudo adalah perintah yang bisa menggantikan user utama yaitu root, sehingga sebagai user biasa kita dapat menggunakan hak - hak dan perintah - perintah yang hanya bisa digunakan oleh root.

Berikut adalah isi file /etc/sudoers sebelum dikonfigurasi :

\# /etc/sudoers

\# User privilege specification

root $A L L=(A L L) A L L$

\# Members of the admin group may gain root privileges

\%admin $A L L=(A L L) A L L$

Edit file /etc/sudoers dengan menggunakan pertintah "nano letc/sudoers" dan tambahkan hingga menjadi :

\# /etc/sudoers

\# User privilege specification

root $A L L=(A L L) A L L$

nobody $A L L=(A L L) A L L$

nobody $A L L=(A L L) \quad$ NOPASSWD: $A L L$

\%root $A L L=(A L L) \quad$ NOPASSWD: $A L L$

\%onobody $\quad A L L=(A L L) \quad$ NOPASSWD: $A L L$

\%admin $A L L=(A L L) A L L$

Setelah kedua file dikonfigurasi maka, lakukan perintah untuk mengcopykan aplikasi pada web browser berikut adalah perintahnya:

1. chmod 777 /opt/lampp/htdocs. Mengubah hak akses direktori web browser agar bisa diakses oleh user siapapun.

2. cp index.php /opt/lamp/htdocs. Menyalin aplikasi ke direktori web browser.

3. Setelah selesai dikonfigurasi maka pengguna dapat menggunakan aplikasi yang bersangkutan. Pengguna memasukan input yang sesuai dengan kepentingan. Output yang dihasilkan disesuaikan dengan input dari pengguna.

Dalam Linux dalam penyimpanan file konfigurasi terletak pada /etc/passwd, file ini ketika kita memasukan perintah maka file akan terupdate.

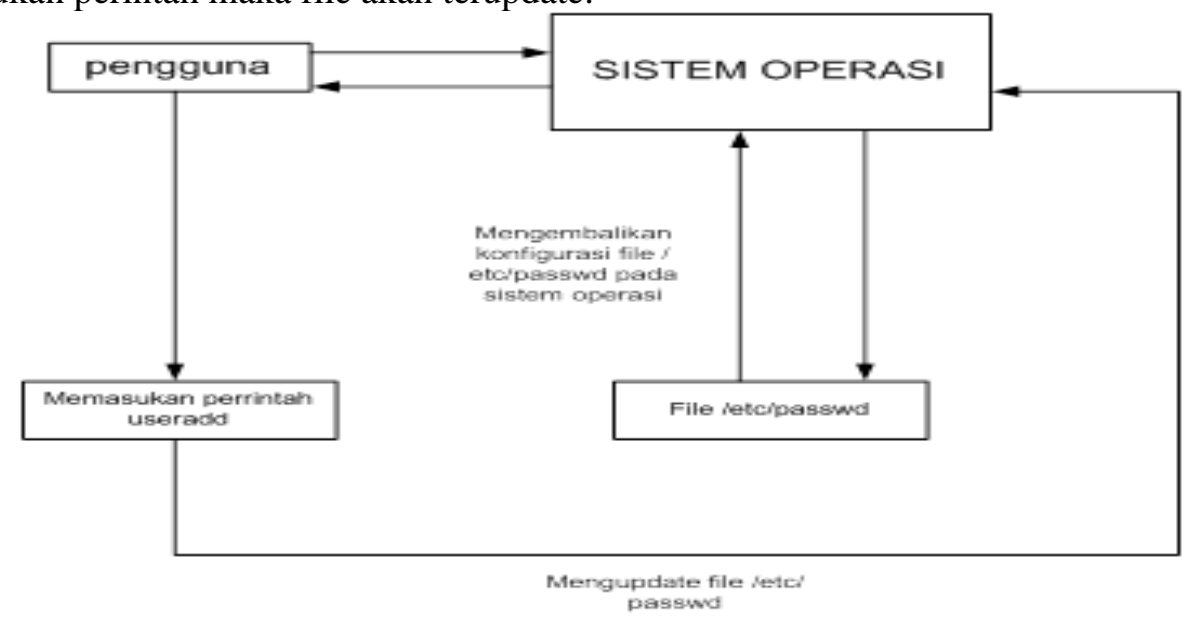

Gambar 3. Diagram Blok Mengupdate File /etc/passwd

1. Pertama pengguna mendapatkan sistem operasi yang belum terupdate file /etc/passwd. 
2. Pengguna memasukan perintah pada sistem operasi, kemudian file letc/passwd terupdate.

3. file /etc/passwd yang sudah terkonfigurasi dikembalikan pada sistem operasi.

4. Sistem operasi menampakan hasil pada pengguna.

Tampilan depan / input

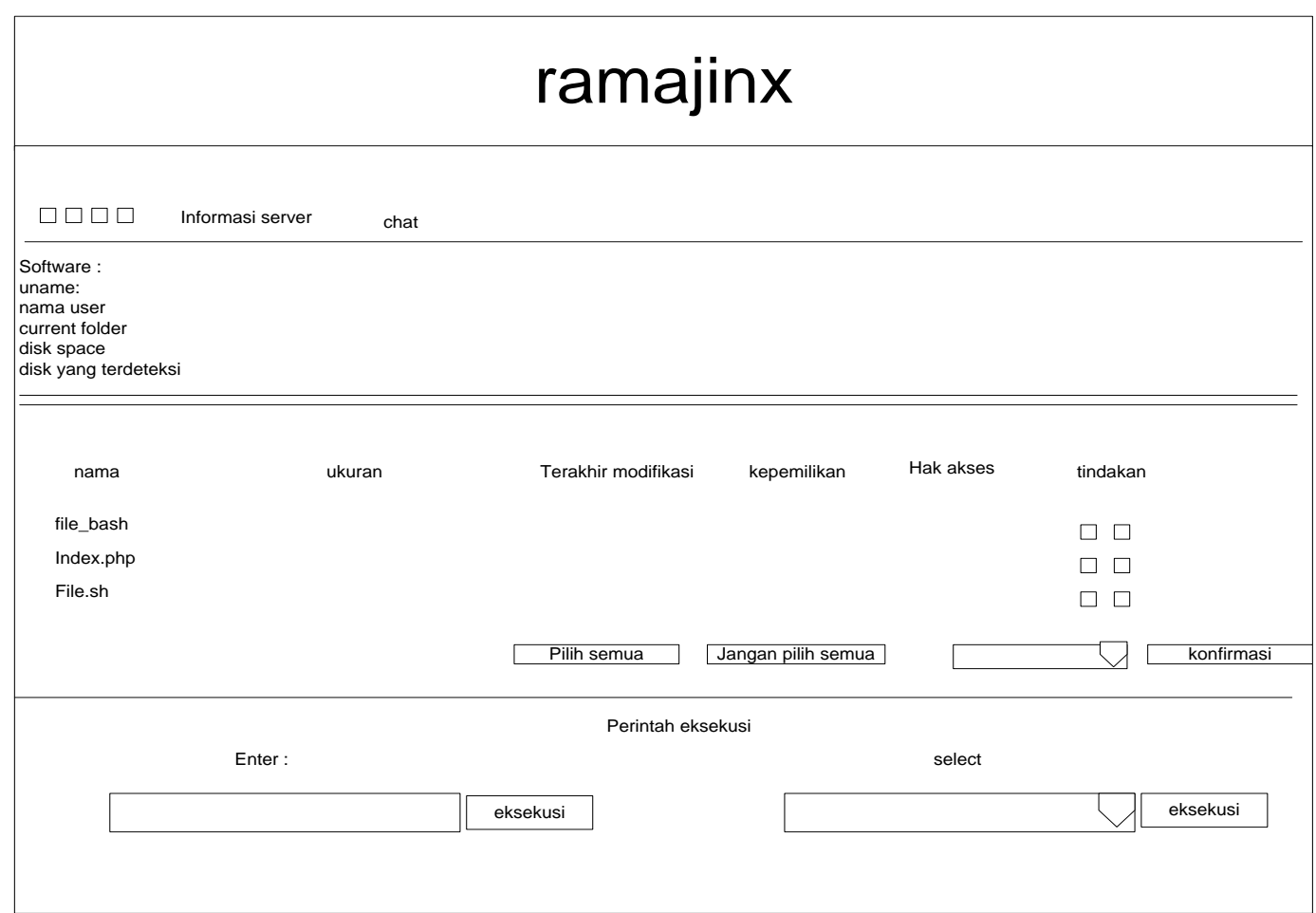

Gambar 4. Rancangan Tampilan Depan / Input

Pada tampilan ini berisikan fungsi :

1. Tombol informasi lengkap, berfungsi untuk mengetahui informasi web server yang dipakai dengan lengkap.

2. chat, merupakan fungsi untuk berkomunikasi pengguna program dengan pengguna Linux.

3. Fungsi perintah, menuliskan perintah sesuai yang kita kehendaki,

4. Perintah cepat, perintah yang sudah tersedia pada badan program sehingga tidak perlu mengetikannya langsung. Fungsi ini berbentuk drop down list.

Desain Output

Desain output berupa file konfigurasi Linux yang telah berubah misalnya file letc/passwd, dan hasil keluaran perintah yang akan dituliskan langsung.

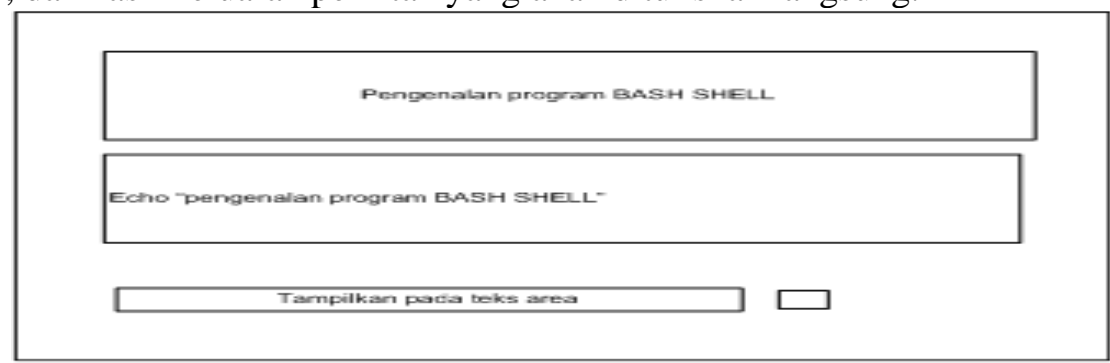

Gambar 5. Tampilan Output 
Gambar diatas mencontohkan output yang terjadi, ketika kita menginput perintah "echo "pengenalan program BASH SHELL" menghasilkan output "pengenalan program BASH SHELL".

Inputan lainnya ada kita dapat mengedit file pada web server, misalkan saja kita mengubah file konfigurasi. Berikut adalah contoh inputan berupa pengeditan file index.php yang ada pada web server XAMPP :

Tampilan Edit File

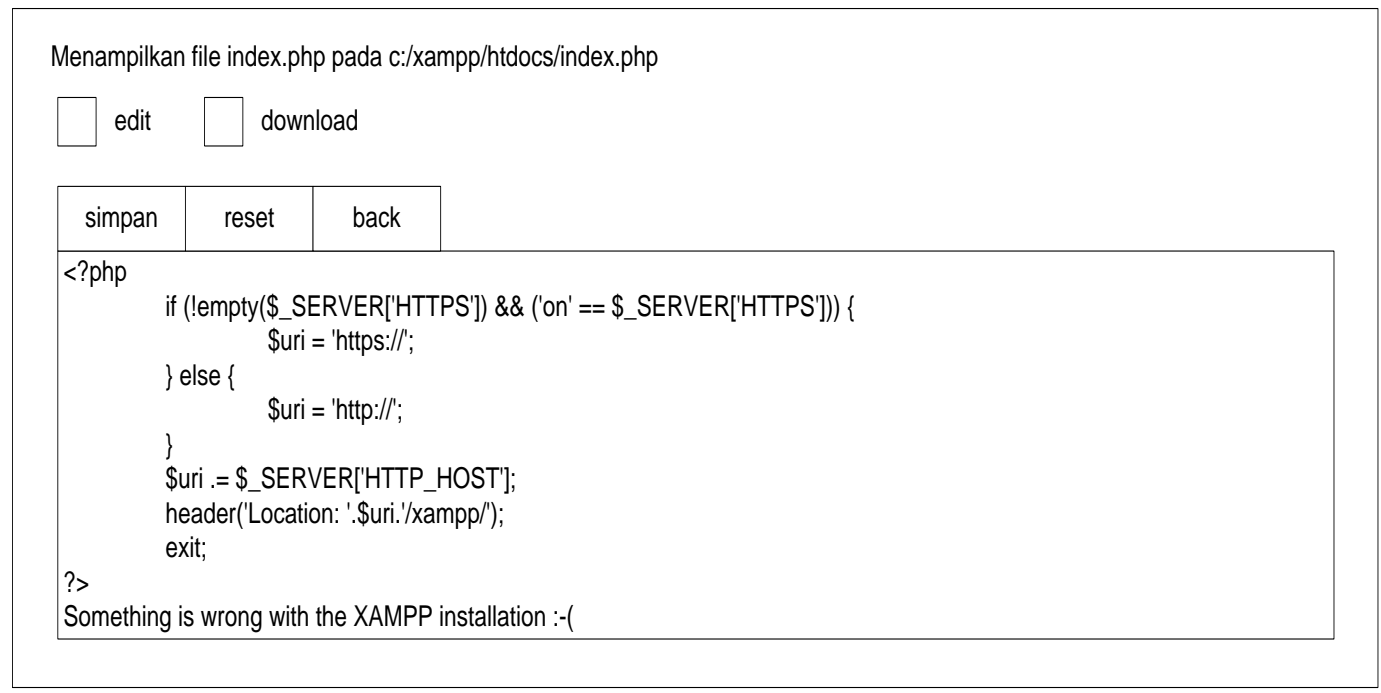

Gambar 6. Fungsi Edit File

Adapun keterangan gambar fungsi edit file diatas adalah sebagai berikut :

1. Teks area adalah isi dari index.php yang akan di edit. Teks area akan bisa di edit ketika tombol edit diatas di klik.

2. Simpan berfungsi untuk menyimpan perubahan file yang kita edit.

3. Reset berfungsi untuk membatalkan perubahan file yang kita edit.

4. Back berfungsi untuk membatalkan fungsi edit.

5. Download berfungsi untuk mengunduh file index.php, baik sudah di edit ataupun belum di edit.

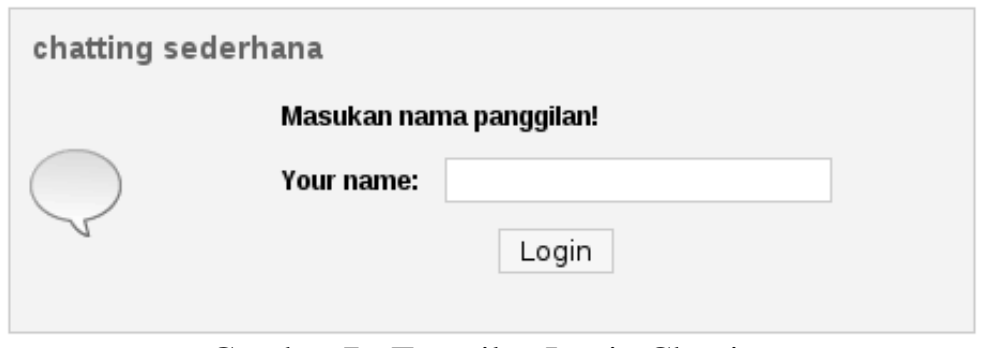

\section{Gambar 7 : Tampilan Login Chatting}

Tampilan pada gambar 7 ini berguna untuk memasukan nickname (nama singkatan) sebagai identitas pengguna chatting. 


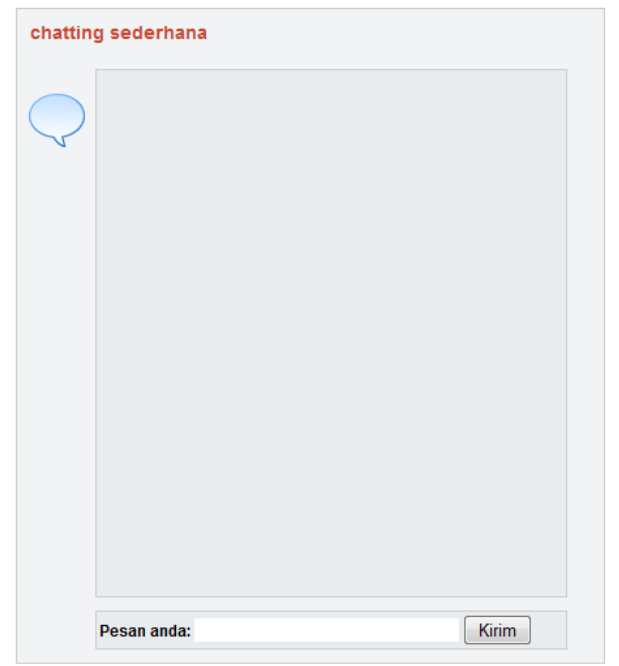

Gambar 8. Tampilan Chatting

Adapun tampilan yang ada pada gambar 8 merupakan wadah dari isi percakapan, percakapan ini tidak berhubungan dengan database, namun menggunakan metode pembuatan file mengunakan $P H P$.

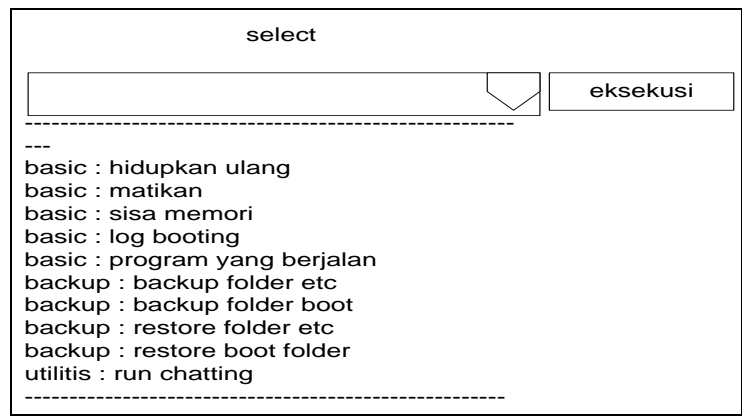

Gambar 9. Tampilan Drop Down List

Adapun tampilan yang ada pada gambar 9 merupakan fungsi - fungsi yang sudah dituliskan pada badan program.

\section{Logika Program}

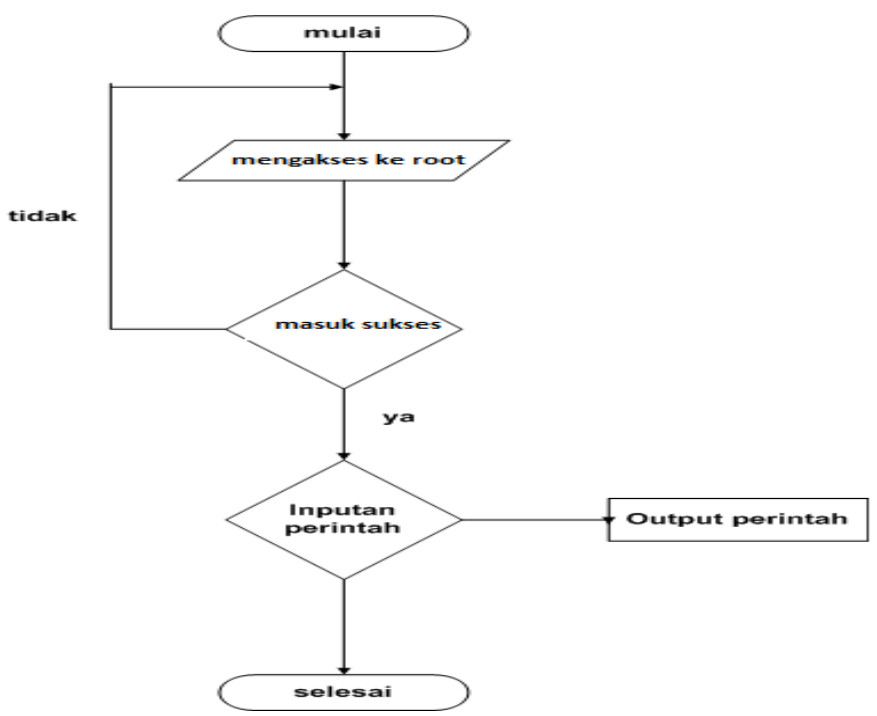

Gambar 10. Flowchart logika program 
Keterangan flowchart sistem :

1. Mulai

2. Masuk kehalaman aplikasi, jika seting Linux sudah sesuai maka kita dapat melakukan inputan perintah pada web browser.

3. Inputan yang kita ketikan pada web browser akan di terjemahkan oleh PHP menjadi perintah langsung yang diketikan pada sistem Linux. Fungsi yang mengubah inputan teks menjadi perintah yang di eksekusi pada sistem Linux adalah PHP Exec.

4. Jika sudah masuk dengan semestinya maka kita dapat menginput perintah yang sudah disiapkan, ataupun kita ketikan secara manual, pengetikan secara manual membutuhkan pengetahuan akan bahasa pemogramman PHP dan pemogramman bash.

5. Inputan yang kita ketikan akan diseleksi oleh sistem Linux, seleksi berdasarkan hak akses perintah dan perintah ada atau tidak pada sistem Linux.

6. Output perintah, inputan yang dibuat menghasilkan output yang sesuai dengan inputan. Output yang dihasilkan dapat berupa tampilan yang tampak pada web browser ataupun output berupa berubahnya file konfigurasi pada sistem.

7. Selesai.

Adapun halaman web browser yang di bangun adalah halaman index.php, halaman yang pertama kali muncul pada saat web browser dibuka. Yang berisikan hampir seluruh dari fungsi aplikasi.

Secara umum tampilan hasil dari aplikasi tersebut :

Tampilan login : memasukan password dan username untuk masuk kedalam aplikasi.

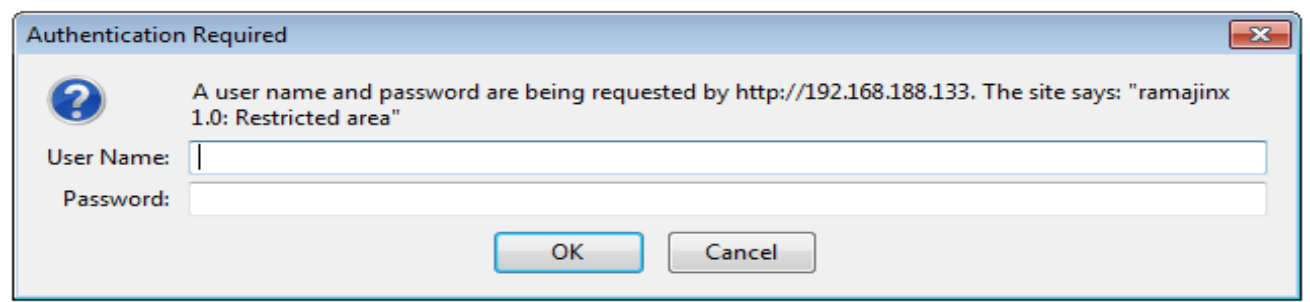

Gambar 11. Tampilan login

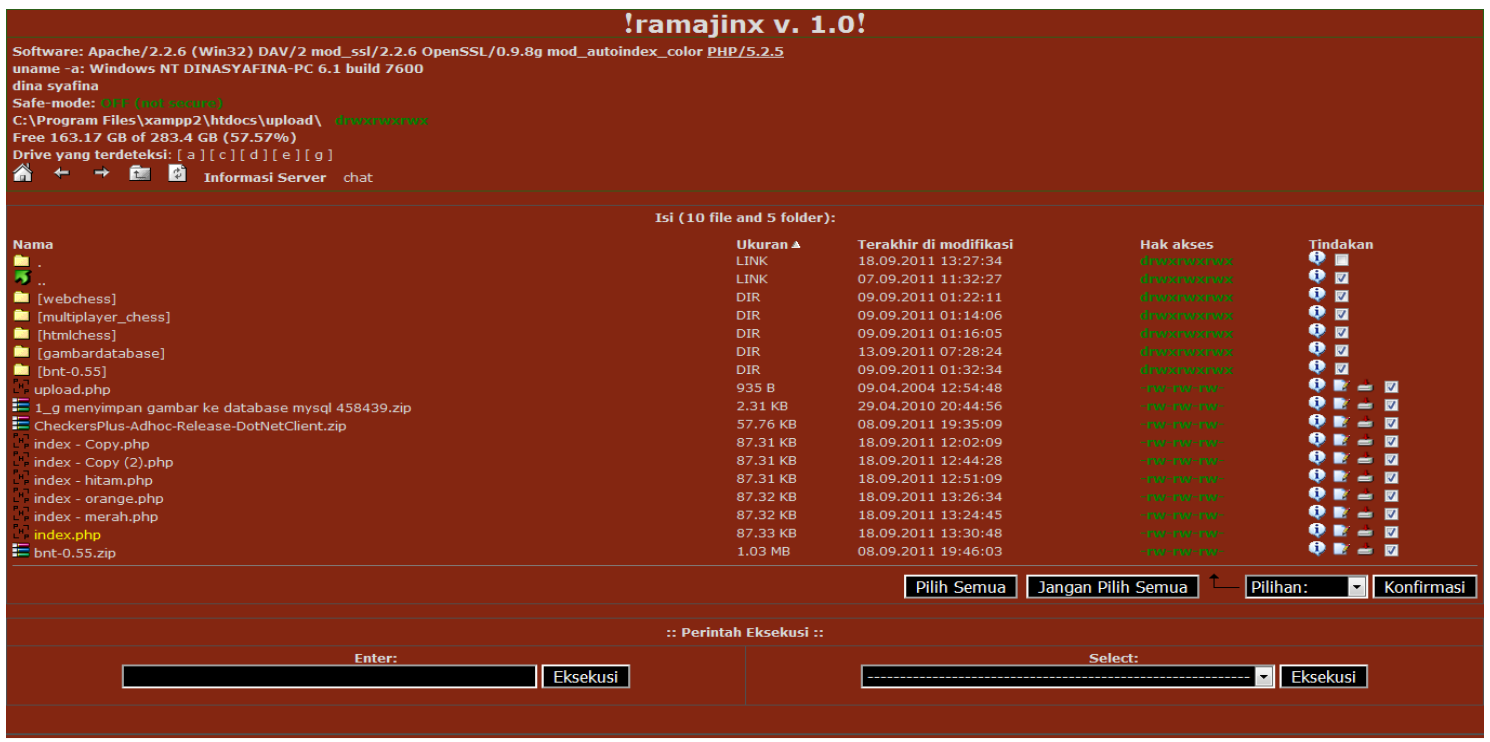

Gambar 12. Tampilan Utama

Tampilan utama : merupakan tampilan utama dari aplikasi ini yang menyajikan input sekaligus output perintah. 
Tampilan output tulisan : Berisikan tampilan output yang tampak pada web browser. Pada gambar 13 merupakan contoh output dari perintah "sudo ps -aux" yang menunjukan proses yang terjadi pada Linux.

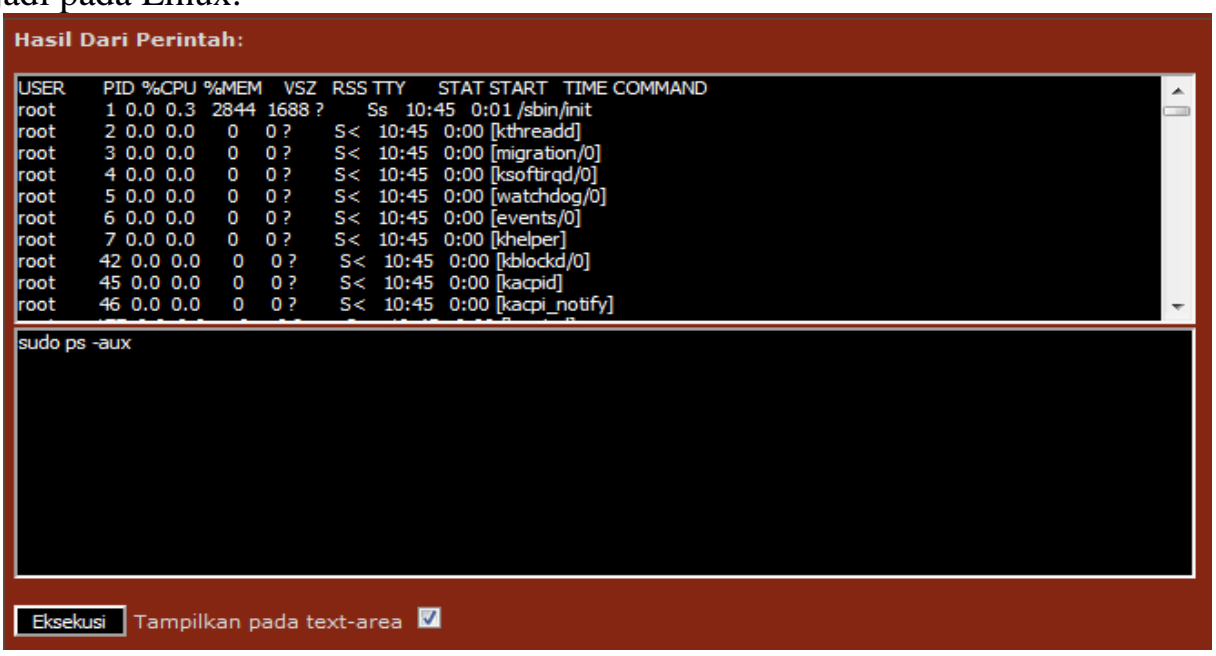

Gambar 13. Tampilan Output Perintah

Tampilan input perintah : merupakan tampilan fungsi untuk memasukan perintah Linux. Pada Gambar 14 merupakan contoh memasukan perintah "sudo ps-aux" pada Linux melalui web browser untuk mengetahui proses yang berjalan pada sistem operasi Linux.

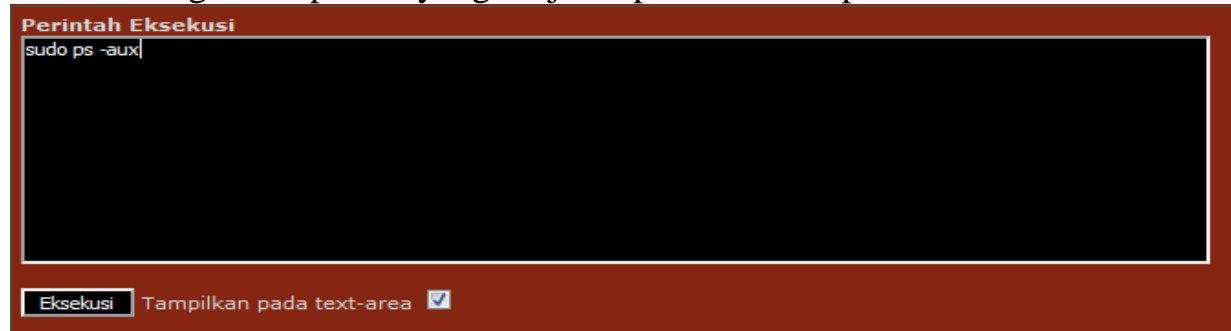

Gambar 14. Tampilan Input Perintah

\section{KESIMPULAN}

Dalam penelitian ini telah diuraikan perancangan aplikasi ini. Dan dapat disimpulkan sebagai berikut :

a. Dengan adanya fasilitas remote desktop melalui web browser dapat memudahkan seseorang dapat mengatur user account atau konfigurasi dari linux

b. Penelitian ini dibuat dengan menggunakan bantuan PHP dan sudah online

c. Penggunaan fungsi PHP Exec pada aplikasi ini tidak hanya dapat digunakan pada sistem operasi Linux saja, namun pada setiap sistem operasi yang dapat diinstalasi perangkat lunak PHP.

\section{SARAN}

Saran-saran untuk untuk penelitian lebih lanjut untuk menutup kekurangan penelitian antara lain:

1. Sebaiknya untuk pengembangan dapat dibuat dengan menggunakan HTML 5 dan berbasis GUI

2. Dapat dibuat dengan menambahkan tentang konfigurasi kernel linux dan web server

3. Ditambahkan ada fitur keamanan antara lain dengan menggunakan username dan password agar dapat mengetahui dan menganalisa paket jaringan yang digunakan dan menggunakan protokol $h t t p$. 


\section{UCAPAN TERIMA KASIH}

Penulis mengucapkan terima kasih kepada Pimpinan dan Yayasan Universitas Potensi Utama yang telah memberi dukungan financial terhadap penelitian ini.

\section{DAFTAR PUSTAKA}

[1] Yusriwa Effendi, 2008, "Desain dan Implementasi Autentikasi Jaringan Hotspot Menggunakan Chillispot Autentikasi System dan Radius Server pada Debian GNU/Linux 4.0 r3 ETCH", Tugas Akhir, Universitas Muhammadiyah Surakarta.

[2] Kamaludin, Agustian, 2014, "Aplikasi Bantu Konfigurasi Jaringan Linux Ubuntu Menggunakan Pemrograman Shell dan Zenity", Laporan Tugas Akhir, Universitas Kristen Maranatha.

[3] Della Safira, 2013, "Kelebihan dan Kekurangan Sistem Operasi Linux", Institut Teknologi Sepuluh Nopember.

[4] Ferri Fadli, 2012, "Penerapan File Server Menggunakan Samba dan LDAP di U'BUDIYAH Indonesia" Skripsi, STMIK U'BUDIYAH Indonesia, Banda Aceh

[5] Basalamah, 2001, Teknologi Digital, Penerbit PT. Elex Media Komputindo, Jakarta.

[6] Widjanarka, Wijaya, Ir, N, 2006, Teknik Digital, Penerbit Erlangga, Jakarta.

[7] Putra.Darma, 2006. Pengolahan Citra Digital, Penerbit Andi Offset, Yogyakarta.

[8] Putra.Darna, 2010. Pengolahan Citra Digital. Penerbit Andi Offset, Yogyakarta.

[9] Wahana.Komputer. 2010. Tutorial 5 Hari Menggunakan GUI Dengan JAVA Netbean 6.5. Penerbit Andi Offset, Yogyakarta. 